ISSN: 0212-0267

DOI: https://doi.org/IO.I420I/hedu202039337356

\title{
LA PEDAGOGÍA DE MILANI EN ESPAÑA E IBEROAMÉRICA ${ }^{1}$
}

\section{Milani's pedagogy in Spain and Latin America}

José Luis Corzo Toral

Prof. emérito de la U. Pontificia de Salamanca

Correo-e: jlcorzo@telefonica.net

Recepción: 5 de junio de 2020. Envío a informantes: 12 de junio de 2020

Aceptación final: Is de noviembre de 2020

Resumen: El autor se fija más en la pedagogía que en los métodos didácticos de la Escuela de Barbiana, cuya Lettera a una professoressa (1967) se tradujo a más de 60 lenguas y nunca ha faltado de las librerías italianas y españolas, traducida como Carta a una maestra por sugerencia de Marta Mata. Ya en 1969 Meri Franco Lao la tradujo para Argentina y Uruguay, de donde pasó a otros lugares de Iberoamérica como Carta a una profesora. La principal aportación de esta Carta es doble: la escuela obligatoria ha de ser compensatoria de los últimos, carentes de la palabra que nos hace iguales. La escuela actual daña más a quienes triunfan en ella sin ver la parte mejor de la humanidad. Esta crítica radical espanta a los partidarios de una escuela competitiva y liberal. Son muchos los pedagogos que la ignoran para rechazarla, o que solo leen en ella un reclamo contra el fracaso y el abandono escolar prematuro. Por eso repasa el autor la lista de profesores, editoriales y revistas que -en España sobre todo- asumen Barbiana y otorgan a Lorenzo Milani un puesto en la pedagogía contemporánea. Por suerte, son muchas más las escuelas populares que se inspiran en sus páginas.

Palabras clave: Pedagogía; didáctica; dar la palabra; escuela compensatoria; escuela competitiva.

ABSTRACT: A survey is conducted here on pedagogy -rather than didactics- as practised in Barbiana School. Lettera a una professoressa (1967) has been translated into more than 60 languages, the finest English versions in Penguin and Random House: Letter To A Teacher. Two are the main insights of the Letter: compulsory

Adaptación actualizada de la Ponencia presentada en las VI Conversaciones pedagógicas de Salamanca: Influencias italianas en la educación española e iberoamericana. Universidad de Salamanca, 6 de junio de 2014 . 
school should make up for the lacks of the deprived, those bereft of the word that sets us equal. As for now, school harms the winners, for they won't look into the better parts of humankind. Such a radical criticism scares away those promoting the competitive, liberal school. Many academics ignore Barbiana to reject it, or just come to read in the School a remedy for dropouts or schoolling failure. A list of university lecturers and professors, printing houses and journals is provided collecting those inspired by Barbiana and setting Lorenzo Milani on top of the contemporary pedagogy scene. Luckily enough, those grassroots schools moved by the Letter are in larger numbers.

KEY WORDs: Barbiana pedagogy; didactics; to give the floor to the mute; compensatory education; competition-driven education.

\section{Introducción}

I en estas Conversaciones salmantinas se habla de Influencias en la edu- cación, deseo centrarme en concreto en las influencias pedagógicas, más que $\checkmark$ didácticas, de Lorenzo Milani (1923-1967) y de sus escuelas de Calenzano y Barbiana (Florencia, Italia) ${ }^{2}$ tanto en España como, con menos datos, en Iberoamérica. La didáctica, aislada de sus raíces antropológicas y sociológicas, por no decir filosóficas o hasta teológicas, aparece como un muestrario de utilidades prácticas multiuso, al que prefiero no exponer a Milani. A pesar de contar con varias innovaciones didácticas muy notables, él merece ser conocido como pedagogo $^{3}$. Y, en cuanto tal, hay que confrontarse con él ante el fenómeno antropológico en general y el crecimiento de la persona humana en sus respectivas sociedades y culturas. Eso aquilata la Pedagogía y me alarma que se confunda con la Didáctica, como a veces hacen los políticos ${ }^{4}$. De hecho, comprender la naturaleza del desarrollo de la persona -si individual o colectivo, si prevalentemente cognitivo o pragmático, si inmanente o relacional, etc.- y de su desarrollo psicológico (Piaget, Vigotsky, etc.) no nos vincula en exclusiva con ninguna praxis didáctica; y todas, a su vez, podrían orientarse correctamente hacia la mejor Pedagogía.

La propuesta pedagógica de Milani es muy radical, es decir, surge de las raíces, como diría Paulo Freire (I92I-1997) y, aunque coetáneos, no supieran uno del otro mientras ambos vivían ${ }^{5}$. No hay duda de que sus propuestas brotaron de las

Predomina el nombre de Barbiana por estar ligada a la Carta a una maestra, pero la experiencia de siete años en la anterior parroquia de San Donato en Calenzano (Florencia) fue decisiva.

El volumen preparatorio de estas Conversaciones, J. M. Hernández Díaz (coord.): Influencias italianas en la educación española e iberoamericana (Fahren House, Salamanca 20I4) ya recoge un estudio de V. González López: «Lorenzo Milani y Paolo Freire. Convergencias y divergencias pedagógicas», pp. 239-250.

4 Algunos políticos actuales en España hablan de «hacer pedagogía»; señal inequívoca de que la confunden con la didáctica.

5. Freire conoció después al de Barbiana y tengo el honor de que haya prologado nuestro libro Don Milani nella scrittura collettiva (en colaboración con F. Gesualdi, exalumno de Barbiana: Torino, Gruppo Abele, 1992). 
raíces más hondas que ellos lograron comprender de la existencia humana. Esas honduras deberían hacer humilde a la Pedagogía. El margen de error y superficialidad de la que es capaz ante tan vasto panorama existencial es enorme. En teoría, lo primero sería determinar cuáles son esos problemas o desafíos radicales (Freire) que han de afrontarse; ello afecta tanto a los progresistas como a los conservadores y, dada la condición cristiana de ambos pedagogos, también a la Iglesia misma. Tanto unos como otros se han sentido muy incómodos ante estos dos maestros y, sin duda, eso determina también la acogida posterior que les han dispensado: mucho más conocido Freire que Milani, tampoco es fácil evaluar hasta dónde se le ha seguido; poco, sin duda, en los terrenos de la pedagogía académica y política.

Como suele pasar entre los grandes maestros de la humanidad, sorprende que la propuesta de Milani (y la de Freire), más que teórica, haya surgido de la vida misma y de un contexto humano muy concreto: su misión entre los campesinos emigrados a la industria en Calenzano y, después, en una aldea de montaña del bajo Apenino toscano llamada Barbiana, que apenas aparece en los mapas. Pero, en cambio, una realidad universal, que le hizo hablar a Ernesto Balducci, el primero de todos, de «las Barbianas del mundo» ${ }^{6}$. El hecho es evidente: la mayoría de los escolares de la tierra viven en alguna Barbiana rural o periférico-urbana. Los pedagogos que escriben libros y dictan conferencias deben decirnos siempre quiénes son y a quién se dirigen con sus pensamientos. No sea que solo piensen para este mundo acomodado en el desarrollo. ¡Bueno sería averiguarlo antes de empezar a leerlos! El número de gente desafiada duramente también cuenta -iy mucho!- a la hora de conocer al ser humano y de ayudar a su felicidad. Sería estúpido a priori pensar que la propuesta alfabetizadora de adultos marginados en el Brasil de Paulo Freire tuviera una acogida entusiasta en la escuela burguesa del arribismo burgués europeo. Y lo mismo pasa con Milani.

No es una casualidad que el descubrimiento de estos autores represente muchas veces para sus lectores una verdadera conversión; más que por sus ideas, por el mundo de los nuevos interlocutores con que ellos hablan. En mi caso, tuve la suerte pedagógica de poder conectar inmediatamente con el mundo inmenso de los excluidos; pero me supuso renegar de mi anterior mundo escolar aprendido. Todavía me duele mucho que la legislación educativa corriente apenas piense en esa «mayoría» global. Hablan del fracaso escolar - una característica natural de esa inmensa mayoría- sin percibir que el fracaso es el nuestro.

\footnotetext{
6 «Il nostro mondo occidentale è ormai in via di rapida omologazione, senza più Est e Ovest, è un mondo che presume di possedere la cultura autenticamente umana. Di fronte al nostro mondo occidentale, le Barbiane del mondo..., perchè Barbiana è un nome emblematico, Barbiana non è più in Mugello: Barbiana è in Africa, è nel Medio Oriente, Barbiana è una comunità musulmana, Barbiana è nell'America latina. Le barbiane del mondo dicono che noi ci comportiamo come se il mondo fossimo noi», Balducci, E.: «I nuovi ragazzi di Barbiana», L'Unità, 26.6.1992; cf. id.: «Los nuevos chicos de Barbiana», Iglesia Viva, 164/165 (mar-jun 1993), pp. 229-237.
} 


\section{Para un primer retrato robot de la escuela de Barbiana y su maestro}

\section{I.I. En cuanto a libros en español}

La obra más conocida es Lettera a una professoressa (Florencia 1967), que en catalán y en español se tradujo como Carta a una mestra (1969) o maestra (Barcelona 1970), aunque en algunos países latinos se mantuvo literal como Carta a una profesora). Su autor, «Scuola di Barbiana», es a veces, con más detalle, «Estudiantes, o Alumnos, de la escuela de Barbiana». En alguna ocasión -no sabemos por qué- titulan «cartas» a una maestra ${ }^{7}$ y, aun en España, se suele oír en plural, pero no es más que una sola carta escrita por varios chicos a la vez.

El libro Esperienze pastorali (1958) es menos conocido, pero fundamental y único libro firmado por Milani. Su venta y traducción fueron prohibidas por el Vaticano hasta, precisamente, el mes de abril de $2014^{8}$. La traducción al español -Experiencias pastorales- es la única hasta la fecha y la realicé dos veces: en 1975 y en 2004, renovada. La primera bajo un título alusivo a la Carta ya conocida y en busca de lectores del medio escolar: Maestro y cura de Barbiana. Experiencias pastorales (Madrid 1975); la segunda, fiel a su título y editada -nada menos- que por la Biblioteca de Autores Cristianos (Madrid, BAC, 2004) propiedad de la Conferencia Episcopal Española ${ }^{9}$, conecta con el mundo de la Teología pastoral.

Existe también una breve antología de cartas milanianas, Dar la palabra a los pobres: cartas de Lorenzo Milani (Madrid, AAC, $\left.{ }^{2} 1995\right)$, y recientemente en catalán L'obediència ja no és una virtut (Barcelona, Rosa Sensat, 20I4), que contiene las cartas relativas al proceso sobre la objeción de conciencia. Otras muchas se hallan en artículos de revista ${ }^{10}$.

I.2. En cuanto a su imagen audiovisual, existe en castellano un documental realizado por Bernard Kleindienst (1994 ARTE Francia), 6o de duración, con exalumnos de Barbiana y notable éxito y eficacia. Fue emitido por la televisión española (TVE 2, I4. I. 2000) y es accesible en Internet: Adiós Barbiana. Para fotos y noticias, la wrwro.amigosmilani.es es el sitio español de referencia. Milani ha sido varias veces llevado al cine y a la TV en Italia.

\section{Buenos Aires, Schapire Editor, 1974.}

8 El monográfico de Educar(NOS), 66 (2014) «El Papa rescata a Milani» da buena cuenta de ello.

Aparte los estudios realizados en universidades de la Iglesia, solo conozco la aportación explícita y doble de un obispo español, Mons. J. Carrera Planas: «El sacerdote de Barbiana», Catalunya Cristiana (I y 8 nov 2007), p. 40.

ı Educar(NOS) dedica una sección fija, «Para beber», a textos milanianos: www.amigosmilani. es. 


\section{I.3. En cuanto a la biografía de Lorenzo Milani (1923-1967)}

En español existen varias biografías de Milani ${ }^{11}$ y en Italia sigue siendo la más completa la escrita por la periodista N. Fallaci (hermana de Oriana ${ }^{12}$. Los rasgos esenciales de su foto robot podrían ser estos: I. $^{\circ}$ Milani era un joven estudiante de pintura; $2{ }^{\circ}$ de ascendencia familiar judía no practicante y alto-burguesa; $3 .^{\circ}$ se convirtió a la fe cristiana a los 20 años en plena guerra (1943); $4 .^{\circ}$ seminarista, de inmediato fue ordenado sacerdote en $1947 ; 5 .^{\circ}$ en una parroquia semirrural e industrial de Calenzano (Florencia) creó una escuela vespertina para jóvenes comunistas y democristianos; $6 .^{\circ}$ tras siete años fue nombrado párroco (priore) de Barbiana, en un «monte perdido» y en suma pobreza; $7 .^{\circ}$ allí hizo escuela a tiempo pleno a las niñas y niños del contorno, hasta su muerte.

I.4. En cuanto a los rasgos más salientes de su pedagogía: . ${ }^{o}$ a los campesinos y obreros que él conoció solo les hacía falta la Palabra, no nuestra visión del mundo; $2 .^{\circ}$ la escuela obligatoria no puede ser selectiva: el último era el preferido y se ayudaban unos a otros; $3 .^{\circ}$ la escuela a «tiempo pleno» permite diariamente leer $y$ discutir en común el periódico; $4{ }^{\circ}$ escribir colectivamente (como la Carta a una maestra); $5 .^{\circ}$ interrogar a los huéspedes; $6 .^{\circ}$ salir de casa $y$ viajar al extranjero para conocer otros ambientes y aprender otras lenguas; $7 .^{\circ}$ todo para ayudar a los otros y no convertir la escuela en «una cloaca de propaganda empresarial».

\section{I.5. En cuanto a su aportación fundamental}

Los pocos rasgos anteriores bastarían para identificar a Barbiana como un ejemplo de apoyo extraescolar a los últimos (dopo-scuola, «después-de-la-escuela») para impedir el fracaso escolar al que conduce, como en España, «una escuela única igual para todos», cuyo fracaso y abandono escolar son altísimos. Y es que «no hay nada tan injusto como tratar igual a quienes son desiguales» ${ }^{13}$ se lee en la Carta que en Italia puso de moda el doposcuola durante la contestación estudiantil de 1968. Por todas partes curas, profesores y estudiantes universitarios daban clases de repaso a la chavalería peor escolarizada en los barrios populares. Era un refuerzo escolar indispensable para una mayoría de chicos del planeta a los que la escuela obligatoria no les basta $y$, encima, los marca para siempre con un fracaso prematuro.

"La primera, también en Italia, es Martí Soler, M.: El mestre de Barbiana, Barcelona, Nova Terra, 1972, en catalán y castellano. Otras dos más breves son de Espigares, T.: Lorenzo Milani, Madrid, CCS, 1995, y de García Domingo, G.: Lorenzo Milani, Madrid, ACC, 2004.

${ }_{12}$ Fallaci, N.: Dalla parte dell'ultimo. Vita del prete Lorenzo Milani, Milán, Milano Libri, 1974.

13 Alumnos de la escuela de Barbiana, Carta a una maestra (Madrid, PPC, $2013^{7}$ ), p. 66. 
Pero el riesgo de tan escasos rasgos es desplazar la escuela de Barbiana fuera del sistema escolar obligatorio (como si fuera algo extraescolar o no formal, como dicen algunos casi con desprecio). Así también logran encasillarla como una más de las llamadas «experiencias»-más o menos exóticas- de actividades didácticas laterales e ingeniosas. Pero, en realidad, Barbiana pone contra las cuerdas al aparato escolar establecido y a nosotros.

\section{I.6. ¿Acaso no era la escuela de un cura?}

Identificarla como escuela parroquial o simplemente «de curas», tal vez, al servicio de la catequesis y de la Iglesia es lo que más deforma el retrato robot de esta escuela. Las posibles conexiones entre la fe cristiana del converso y sacerdote don Milani (título que en casi toda Italia se reserva exclusivamente para los sacerdotes) y su escuela no son fáciles de explicar. Se requiere una atención especial para comprender, por ejemplo, que su escuela, según él, era y debía ser a-confesional. De hecho, su peculiar forma de entender la misión de la Iglesia (teología pastoral) le hacía descubrir muchas realidades de la vida y muchos conceptos que, decía, son intrínsecamente sobrenaturales, pero no necesitan la «mención explícita del Nombre del Amo». Para él, la palabra «de Dios» no lo es por añadirse a las nuestras, sino por encarnarse en ellas. De ahí su amor a las palabras y este raro milagro ya comprobado: los lectores laicos no extrañan nada en sus escritos y a los cristianos no les hace falta mencionar a cada paso al Amo. De hecho abundan los estudios laicos de la escuela de don Milani, mientras que los teológicos escasean ${ }^{14}$.

Pero nada de eso se ve a primera vista. Y ahí sigue: demasiado cura para quienes ven su sotana en las fotografías o sospechoso si habla poco de Dios y no quiere que su escuela sea confesional. Repele a ciertos anticlericales y, por su laicidad, a los cruzados de la escuela católica.

\section{I.7. Su lugar entre las tendencias pedagógicas contemporáneas}

Situarle depende de los criterios de clasificación adoptados; así que prefiero no aventurar mi propia clasificación, máxime porque don Milani apenas cita en ninguno de sus escritos autor alguno ${ }^{15}$. No era un estudioso de pedagogía. Pero

${ }_{14}$ Puede verse Conzo, J. L.: Don Milani: la palabra a los últimos, Madrid, PPC, 20I4; Lorenzo Milani, maestro cristiano. Análisis espiritual y significación pedagógica, Salamanca, UPSA, I98I; ambos también en italiano (Brescia, La Scuola, 20I3) y el segundo (a cura di F.C. Manara: Sotto il Monte BG, Servitium, 2008.

${ }_{15}$ Entre las escasas referencias a otros autores existe una alusión a dos pedagogos con los que preparar exámenes de sus chavales: «Non so se il maestro Quercioli ti disse al telefono che libri di pedagogía consigliava a questi ragazzi. Se non l'ha fatto ti prego di domandare ai tuoi amici maestri quale sia il più importante dei libri del Dewey e del Makarenko (si scriverà così?)». L. Milani a G. Pecorini 5.II.I962, en Pecorini, G. (a cura di): Lorenzo Milani, I Care ancora, Bologna, EMI, 20oI, pp. 255-256. 
podemos aportar alguna observación: por ejemplo, la sintonía -muda, como dijimos- con Paulo Freire. Hay alguna más explícita, incluso biográfica, con Mario Lodi (I922-20I4), el maestro de Piadena ${ }^{16}$, considerado como el Celestin Freinet italiano, dentro de la escuela cooperativa, activa, popular y hasta socialista, en línea con la mejor renovación pedagógica italiana del siglo xx, con María Montessori (I870-1952) a la cabeza. Implícitos también hay acordes en su concepción de lenguaje con el más radical y marxista Antonio Gramsci (I89I-I937). En cambio, no me consta por ahora relación o comentario recíproco alguno entre don Milani y otros comunistas contemporáneos suyos, como Gianni Rodari (I920-1980) o el también pedagogo italiano Bruno Ciari (1923-1970), discípulo de Codignola (I8851965), en el Magisterio de Florencia.

Sería más difícil armonizar a don Milani con otro coetáneo suyo, Ivan Illich (I926-2002), a pesar de algunas coincidencias en la denuncia del sistema escolar. Don Milani es un apasionado defensor de la escuela y no quiere desescolarizar la sociedad.

La revista española Cuadernos de Pedagogía incluyó a Milani en el año 2000 en su selección de solo once pedagogos del siglo xx, pero renunció a clasificar$\operatorname{los}^{17}$. La lista es interesante, dado además el prestigio de la revista catalana en todo el mundo hispanohablante: María Montessori, F. Ferrer y Guardia, John Dewey, F. Giner de los Ríos, Celestin Freinet, A. S. Neill, A. S. Makarenko, Jean Piaget, Lorenzo Milani, Paulo Freire y L. Stenhouse. La revista -consciente además de que «hoy en día se aprecia una obsesión, deliberada o inconsciente, por borrar el pasado colectivo, por desterrar de los discursos educativos actuales los referentes y las raíces...»-18, dio explicaciones sobre su propia selección y citó los autores que «saltaron del listado definitivo», aunque pueden ayudarnos a formar nuestro propio mapa pedagógico contemporáneo: «Ferrière y la Escuela Nueva; Decroly y la globalización; Lobrot y la pedagogía institucional; Rogers y la pedagogía no directiva; Steiner y la pedagogía Waldorf; Bruner y la psicología cognitiva; Krishnamurti y el orientalismo; Holt y la desescolarización; Mendel y la pedagogía psicoanalítica; Sensat y la escuela pública y activa; Piussi y la diferencia sexual» (ibidem, p. I2).

${ }_{16}$ Se conservan las cartas en las que intercambiaron sus experiencias de escritura colectiva.

${ }_{17}$ La revista había publicado en su n. ${ }^{\circ} 253$ (1996) un monográfico de «Tendencias educativas hoy» que sin incluir Barbiana señalaba dos negativas, «neoliberalismo y escuela tradicional», y diez más: «democracia, extraescuela, tecnologías, psicologías, currículo, globalización, entorno, diversidades, profesorado y pedagogías críticas». Se remontaba al clásico Palacios, Jesús: La cuestión escolar, Barcelona, Laia, I979, que tampoco incluyó Barbiana. En el año 2000 Cuadernos publicó una biografía en cada uno de sus once números y, después, los reunió en un solo volumen: Pedagogías del siglo XX, Barcelona, Cuadernos de Pedagogía, Ciss Praxis, 2000, Milani en las pp. II9-I29.

i8 Carbonell, J.: «Prólogo. La memoria, arma de futuro», ibidem, pp. 5-I2; y añade: «Mucho se ha discutido sobre el poder del Estado y de sus administraciones educativas para integrar, devaluar, tecnificar y vaciar de contenido las pedagogías innovadoras» (p. 7). 


\section{La acogida en Iberoamérica de Milani y Barbiana}

La suerte que Barbiana y don Milani hayan corrido en la América Latina no se vincula forzosamente con lo sucedido en España. Las conexiones directas con Italia hicieron conocer allí tan pronto como aquí la Carta a una profesora, verdadero pistoletazo de salida de la fama de Milani hasta en la propia Italia. De hecho, su único libro anterior, Experiencias pastorales, 1958, tuvo un público claramente clerical -aunque también lo leyeran muchos laicos- y, de hecho, chocó frontalmente con el Santo Oficio del Vaticano. Eso también frenó su traducción (apenas iniciada en Francia) y hubo que esperar a 1965 para que un proceso abierto contra don Milani por defender la objeción de conciencia antimilitar le hiciera famoso también fuera de Italia, en Inglaterra y Alemania sobre todo. Pero sin duda fue la Lettera a una professoressa, publicada en 1967 , apenas un mes antes de la muerte del cura y maestro de Barbiana, la que inició su presencia pública y el retorno a sus textos anteriores. Una colección de cartas privadas fue un best seller de ventas en $1970^{19} \mathrm{y}$, a partir de ahí, se produjo un aluvión de estudios y publicaciones que aún no ha cesado.

En estas conversaciones iberoamericanas se encuentra también Portugal, pero confieso mi ignorancia inexcusable sobre la suerte de la Pedagogía de Milani en la nación hermana.

En Iberoamérica la edición más temprana que conocemos de la Carta se hizo en Uruguay: Estudiantes de Escuela de Barbiana: Carta a una profesora, traducción y prólogo de Meri Franco-Lao, Montevideo, Biblioteca de Marcha, I969. Por desgracia no puedo asegurar que no haya otras, pero conozco también la realizada en Argentina (donde el título -sin mencionar autor- incorporó un extraño plural): Cartas a una profesora, Buenos Aires, Schapire Editor, I974, con traducción y prólogo de la misma Meri Franco-Lao ${ }^{20}$. Y en México: Alumnos de Barbiana, Carta a una profesora, México DF, Ediciones de Cultura Popular, 1975', 1977, 1978, en traducción anónima diferente de la anterior. Y en México también: México, Ediciones Quinto Sol, 2000 ${ }^{21}$. Es muy probable que haya otras ediciones en otros países, aparte de la exportación librera de unos a otros, incluida España.

Respecto a otros escritos de Milani, en 1995 me encontré con una sorpresa en Bolivia del todo inesperada: existe un Catecismo muy original -siguiendo la vida de Jesús en los cuatro evangelios- escrito por Milani durante sus primeros años de sacerdocio. Pero poco después lo abandonó y al final de su vida no quería siquiera que otros lo utilizaran. A pesar de todo, su alumno Michele Gesualdi lo editó en I982, sin que sea fácil deducir las razones del rechazo de su autor $^{22}$. Pues bien, dicho texto lo encontré traducido en Camiri, una región guaraní

19 Gesualdi, M. (a cura di): Lettere di don Lorenzo Milani priore di Barbiana, Milano, Mondadori, I970.

${ }_{20}$ El texto completo esta en http://es.scribd.com/doc/17298240/Cartas-a-Una-Profesorar.

${ }_{21}$ Cf. Sassoon, Y.y Paredes, J. G.: «La escuela de Barbiana», Correo del Maestro, n. ${ }^{\circ} 94$ (marzo de 2004).

${ }_{22}$ Gesualdi, M. (a cura di): Il Catechismo di don Lorenzo Milani. Documenti e lezioni di catechismo secondo uno schema storico, Firenze, LEF, 1982. Para su elaboración y rechazo cf. Corzo, 
asistida por franciscanos italianos, muy entregados a la conservación y formación de maestros de aquella genuina cultura y de su lengua. El texto se titula Jesús nuestro maestro y en una nota inicial declara su conexión con la Carta a una maestra, ignoro en qué versión ${ }^{23}$.

Sin posibilidad ni pretensión alguna de ser exhaustivo respecto de la divulgación barbianesa en Iberoamérica, me atrevería a señalar como una de las más significativas y conocidas una producción radiofónica del Serpal (Servicio Radiofónico para América Latina), cuyo origen [supongo que financiero y tal vez técnico] es alemán: Radiodienst Vox Christiana; al parecer, alcanza una notable difusión en numerosos países de aquel continente. Se encuentra dentro de un programa radiofónico educativo titulado Jurado I3 (el propio radioyente, el grupo de personas en formación, es uno más de las doce personas que forman los jurados populares), elaborado y dirigido por Mario César Kaplún. Entre los diferentes juicios a presuntos delincuentes se encuentra El caso del niño desertor (llamado allí «Domingo Suárez»): son 3 piezas de 24 minutos cada una y en la 2. ${ }^{\text {a }}$ se menciona y se cita directamente la «Carta a una profesora por los Estudiantes de la Escuela de Barbiana, que plantea el mismo problema, el de los hijos de los pobres que fracasan en sus escuelas». «Dejemos hablar a sus páginas, dice el narrador; si Domingo supiera hablar, lo haría como aquellos chicos...». Y se da lectura ante el tribunal a varios párrafos de la historia de Gustavito (el Pierino del original italiano, hijo de padres universitarios) y de Juan (el chaval repetidor y, a la postre, desertor o fracasado escolar) ${ }^{24}$. El autor de la serie Jurado iz confesó que «I972 fue el año en que se concluyó la producción de la serie y en el que esta comenzó a difundirse. En realidad, como proyecto, como idea, nació aún cuatro años antes. No es casual que haya sido concebida precisamente en i968, el año de la Conferencia de Medellín» ${ }^{25}$. Interesante esta cronología latinoamericana, cuyo paralelo europeo fue nada menos que el mayo francés -y no solo- del 68. Pero la principal sintonía iberoamericana con Barbiana no dependía del acontecimiento eclesial de Medellín, favorable a la teología de la liberación, sino de una realidad social innegable: la escasa y mala escolarización de tantísimos niños y niñas en muchos países. La misma que aún aguarda a Barbiana en África.

\footnotetext{
J. L.: «Lorenzo Milani. El Catecismo cronológico sobre la Vida de Jesús y el mapa de Palestina», Cristianesimo nella Storia (20I4) en prensa.

${ }_{23}$ Lo editaba el Teko Guarani, Camiri (Bolivia), y pude hacerme con una 2. ${ }^{a}$ edición fechada en 1992 con esta Introducción: «Este trabajo no es producción original nuestra. Fundamentalmente nos hemos servido del material usado por don Lorenzo Milani, el maestro de los chicos que escribieron la famosa Carta a una maestra».

${ }_{24}$ Pueden oírse los 3 capítulos en http://radioteca.net/audio/3-el-caso-del-nino-desertor-i/ dentro de la serie de Ediciones Serpal: http://radioteca.net/audioseries/jurado-I3/. Es de notar que también pertenece a esa productora la famosa serie radiofónica de los hermanos José Ignacio y María López VigiL: Un tal Jesús, «que comenzó a escucharse en la mayoría de los países latinoamericanos en los primeros meses de I980» y se halla editado como libro en dos tomos: Salamanca, Lóguez Ediciones, ${ }^{2} 1984$.

${ }^{25}$ Kaplún, Mario César: A la educación por la comunicación. La práctica de la comunicación educativa (2. ${ }^{a}$ edición), Quito-Ecuador, Ediciones CIESPAL, 200I, p. 76.
} 


\section{La acogida de Milani y Barbiana en España}

Aquí no hubo revolución cultural de «mayo del 68»; a la dictadura franquista le quedaban aún siete años de vida y, como en Italia, nuestra Ley General de Educación (LGE 1970, Villar Palasí) acababa de unificar por entonces -para todos los escolares españoles- una misma escuela obligatoria hasta los I4 años. Precisamente la Carta de Barbiana era una severa crítica al modo engañoso con que se realizó en Italia esa unificación. Aquí, mientras crecía el turismo y el contacto con el resto de Europa, crecía la inquietud política y cultural y una soterrada renovación pedagógica, mediante ciertos movimientos y escuelas de verano que -desde Cataluña, Rosa Sensat principalmente- fueron proliferando aquellos años. Que se recuperaran o no los viejos ideales de la Escuela Moderna, o que se impusiera la mentalidad burguesa que hoy domina nuestra escuel ${ }^{26}$, es discutible, pero en absoluto baladí. Lo mismo sucedería después con la Reforma socialista (LOGSE 1990): ¿ha recuperado la mejor renovación pedagógica popular? Es altamente improbable.

Para comprender la acogida, desprecio o rechazo, que Barbiana despierta en la pedagogía oficial y en la masa del profesorado, veterano o nuevo, que llega a conocerla, hay que percibir desde el principio que su aportación fundamental es una verdadera alternativa: la escuela básica no solo ha de ser compensatoria -doposcuola- para repescar a los últimos, sino una verdadera contraescuela ${ }^{27}$. Pero muy pocos perciben a la primera que en la Carta el éxito escolar no es ventaja, sino la peor de las trampas:

Una escuela que selecciona destruye la cultura. A los pobres les quita el medio de expresión. A los ricos les quita el conocimiento de las cosas.

Gianni es un desgraciado porque no sabe expresarse; afortunado él que pertenece al gran mundo. Hermano de toda África, Asia y América Latina. Conocedor desde dentro de las necesidades de la mayoría.

Pierino es afortunado porque sabe hablar. Desgraciado porque habla demasiado. Él, que no tiene nada importante que decir, que sólo repite cosas leídas en los libros, escritas por otro como él... (ibidem, p. I07).

Un jaque mate a la escuela oficial no agrada en absoluto a quien solo busca refuerzos y mejoras para ella. Ni siquiera recuerdan que esta escuela ya nació selectiva: era solo para la burguesía y, después, se fue abriendo a todos. Así que, sin un neto análisis crítico «de clase», Barbiana no puede entusiasmar. Lo normal es que, como mucho, se comprenda en dos mitades: como algo asistencial, un refuerzo muy deseable contra el fracaso escolar y -ya menos- como alternativa radical a la escuela obligatoria.

26 Roig Pérez, Olga: «La Escuela Moderna y la renovación pedagógica en Cataluña», Germinal, I (abril 2006), pp. 75-83.

${ }_{27}$ De hecho, el folleto Scuola popolare di Donato, S.: Doposcuola di classe. L'esperienza di Calenzano, Pistoia, Centro di Documentazione, 1971, lo tradujo J. Gómez y Fernández Cabrera como Contraescuela. Por una escuela popular, Madrid, Zero Zyx, I973. 


\section{I. Los primeros pasos en la difusión de don Milani}

La lectura de Carta a una maestra fue un éxito en Cataluña y en España entera desde el principio, como prueban sus numerosas ediciones que no han cesado aún durante más de 40 años. Es fácil a estas alturas distinguir dos centros españoles de difusión de don Milani: el catalán, a cargo principalmente de Miquel Martí2 ${ }^{28}$ y otro en Salamanca, gracias a la fundación en i97i de la Casa-escuela Santiago Uno y, en 1980, de la Escuela Agraria Lorenzo Milani, todavía vivas y florecientes. En 1982, unos y otros legalizamos juntos un Movimiento -de renovación pedagógica- de Educadores Milanianos (MEM) con sede en Salamanca y ámbito nacional. Es el que ha editado trimestralmente 63 boletines (1982 a 1997) y 68 números de la revista Educar(NOS) desde 1998 hasta hoy. A ambos polos se deben la mayoría de publicaciones milanianas en español, que no son pocas.

La Unesco representó una aportación notable al conocimiento de Barbiana en España (y no solo). Su revista El Correo de la UNESCO, junio 1972, en un monográfico titulado «Una gran encuesta de la Unesco. Fracaso escolar y origen social de los alumnos» dedicaba 6 páginas a Carta a una maestra de escuela (pp. I2-16 y 34). La revista, en I2 idiomas y con altísimo prestigio mundial, editada en Francia bajo la dirección de Sandy Koffler, prestó a la escuelita de Barbiana la máxima atención y respeto posible. Conviene subrayarlo.

No fue la única ocasión en que la Unesco se ocupara de don Milani. El Instituto de la Unesco para la Educación, con sede en Hamburgo, contó con una ponencia nuestra -a cargo del Ministerio de Educación y Ciencia- en un seminario de su Plan Alpha [de adultos] celebrado en Namur (Bélgica) del io al iz de octubre de 199r: una aportación del todo milaniana recogida en varios idiomas ${ }^{29}$.

Pero además, gracias al tesón de Miquel Martí, alma y coordinador a nivel estatal del Plan de Escuelas Asociadas de la Unesco (PEA) durante dos periodos (1990-1995 y 2002-2005), el MEM como movimiento de renovación pedagógica se asoció en 2002 al PEA/Unesco, y lo mismo hizo la Escuela Agraria Lorenzo Milani de Salamanca. Tanto, que ambas entidades organizaron en Salamanca el

28 Tradujo inmediatamente la Lettera a una professoressa al catalán: Carta a una mestra, Barcelona, Nova Terra, 1969; hoy en Vic, Eumo Editorial, 1998. La opción mestra (y no profesoressa como en italiano) la atribuye al consejo de Marta Mata, la gran pedagoga catalana. Hoy conocemos hasta I5 ediciones en castellano: Madrid, PPC, 1996, 20137, traducción colectiva de la Casa-escuela Santiago Uno.

29 Corzo, J. L. y Lancho, J.: «Pertenecer a la masa y dominar la palabra. Una cultura adulta», en Hautecoeur, J. P. (ed.): Alpha '92. Estrategias para la alfabetización, Hamburgo, Instituto de la UNESCO para la Educación, ed. española, Madrid, M. de Educación y Ciencia, 1992, pp. 474-495. Versión francesa: «Appartenir à la masse et maitriser la parole: une culture adulte», en Alpha 92. Recherches en alphabétisation, sous la direction de Jean-Paul Hautecoeur, Québec, Ministère de l'Éducation du Québec, Institut de l'UNESCO pour l'education-Hambourg, 1992, pp. 397-4I8; versión inglesa: "Adult education: literacy for the masses», en Alpha 92. Current Research in Literacy, Edited by Jean-Paul Hautecoeur, Quebec, Unesco Institute for Education and Ministry of Education, 1992, pp. 373-392. 
XX Encuentro nacional de Escuelas Asociadas de la Unesco en julio de 2007, con ocasión del 40 aniversario de la muerte de Milani ${ }^{30}$.

Vida Nueva, revista católica muy leída, editada por PPC desde hace más de medio siglo, también tuvo influencia en la primera difusión de Milani en España, pues otorgó el primer premio al pliego «Dar la Palabra a los pobres. Don Milani», Vida Nueva, 973 (1975), pp. 24-31, que yo mismo había presentado al concurso. Podría recordar mucho de lo que surgió de allí después.

Cuadernos de Pedagogía, como ya dije, significó en el año 2000 un impulso decisivo a la aceptación de Milani, al colocarlo entre los once pedagogos del siglo xx. Pero no lo había hecho así desde el primer momento ni fue la primera revista en ocuparse de él. Al hacer el balance para mi tesis doctoral -en 1980- sobre la recepción de la Carta en Italia y en España ya señalé su inconcebible omisión en un monográfico de Cuadernos en 1976 sobre «La educación en Italia»-¡nada menos!- que es imposible de describir desde el 68 para acá sin mencionar Barbiana ${ }^{31}$. Ante nuestra crítica, Cuadernos reaccionó positivamente y su primera alusión explícita data de $1979^{32}$. Repitió en varias ocasiones, hasta el hecho curioso de haber

30 Martí Solé, M.: Escuelas de futuro. El Plan de Escuelas Asociadas de la Unesco en España, Las Rozas (M), Wolters Kluwer, 20I3. Cf. en pp. II9-I2o lo relativo a aquel encuentro.

${ }_{31}$ En una entrevista en catalán preguntaron al historiador italiano Carlo Ginzburg (Turín I939): «Fins a quin punt el va marcar, a vostè, el maig del 68?». «... Crec que ho va escriure Adriano Sofri, però és una cosa que han dit molts altres, i és que el llibre més important per al 68 a Itàlia va ser un llibre que es diu Lettera a una professoressa, que es va publicar el 1967, escrit per un capellà catòlic, Don Lorenzo Milani, una figura estranyíssima que, per les seves posicions de radicalisme de classe, tot i ser molt capellà, havia estat exiliat per la cúria de Florència en un poblet del Mugello, als turons. Allà, als nens, que no eren de família gaire culta, els feia llegir una introducció a Plató, els donava una educació molt refinada, i amb ells va escriure un llibre en forma de cartes a una professora de la qual no es diu el nom però que existia, que havia supès un noi; d'això, en feia un discurs sobre la cultura, amb una violència de classe que, per a qui estigués avesat a la premsa comunista, era absolutament inaudita. Sí, crec que vaig ser influït per aquest llibre» MuÑoz, J. M.: «Carlo Ginzburg, les traces de la història. Entrevista a C. Ginzburg», L'Avenç, 375 (20I2), pp. I6-25. Algo así se encuentra en el testimonio de Pasolini, P. P.: «La scuola di San Donato e Barbiana e la Lettera a una professoressa. La cultura contadina della scuola di Barbiana», Momento, Milano, i5-I6 (1968), pp. 58-6r; o en el del editor español Mario Muchniк: «En diciembre de 1967 Los hijos de Sánchez, de Oscar Lewis, era lectura poco menos que obligada, sobre todo si uno vivía en París e intuía que las cosas se estaban moviendo; porque los estudiantes de medio mundo lo estaban haciendo, porque ya había salido la Carta a una maestra en Italia [...], obra colectiva de una escuelita rural dirigida por don Milani, un sacerdote revolucionario sin saberlo, que ya plasmaba algunos lemas que serían pintados en las paredes de la Sorbona en mayo del año siguiente. Por ejemplo: ser culto significa pertenecer a la masa y tomar la palabra» (Obituario de A. Orfila, El Mundo, I6.I.1998).

32 Corzo, J. L.: «¿Quién es don Milani?», Cuadernos de Pedagogía, 57 (1979), p. 38. Y la siguiente: Corzo, J. L.: «La incidencia de Barbiana en las estructuras educativas», ibidem, 89 (1982), pp. 9-I2. Con ocasión del XX aniversario de Milani, junto a un nuevo artículo conmemorativo Corzo, J. L.: «¿Qué queda de Barbiana? Milani, veinte años de vida»- se tradujo del italiano una exclusiva entrevista a la verdadera destinataria de la Carta a una maestra, la profesora Spadini: Sofri, A.: «Entrevista a una maestra. Y yo suspendo a don Milani», ibídem, I54 (1987), pp. 85-93. Y todavía antes del antológico 2000 se ocupó la revista de dos didácticas características de Barbiana: Corzo, J. L.: «Periódicos en clase», ibídem, 165 (1988), pp. 20-22; «El nosotros en la escritura colectiva», ibídem, 216 (1993), pp. 66-67. Por fin, en 2007, en el 40 aniversario de Milani: Carbonell, J.: «Carta a una 
nacido una estrecha amistad entre los milanianos españoles y Fabricio Caivano, el creador en 1975 y primer director de la revista durante tantos años ${ }^{33}$. Su segundo director, J. Carbonell, realizó en 1995 personalmente una visita y reportaje sobre el «Centro de FP Agraria Lorenzo Milani. Una escuela a pleno tiempo» ${ }^{34}$.

La bibliografía española completa aportaría al lector las revistas y artículos más tempranos en la recepción de Barbiana ${ }^{35}$. Pero nunca encontraría, por desgracia, alguna editorial especializada en educación que se haya molestado en traducir y editar originales de Milani y estudios italianos de gran interés. El silencio de Escuelas Católicas (antes FERE), tan poderosas en España, es atronador.

\subsection{El nudo de la cuestión}

Una anécdota de los primeros pasos de Barbiana en España retratará mejor que ninguna otra explicación la acogida completa que se le pudo dispensar entonces. Tras la muerte de Franco explotó aquí la transición política en todos los terrenos y también en lo educativo. En Salamanca también había un buen grupo de trabajadores de la enseñanza muy activo e innovador, que, como «Equipo-escuela», nutría de «Educación como tema» algunas páginas semanales del más liberal de los dos periódicos salmantinos, El Adelanto. También existía ya en la ciudad, desde 197I, y bajo la inspiración directa de Barbiana, la «Casa-escuela Santiago uno» (por la calle y el número donde se hallaba junto al Puente Romano, bajo la puerta sur de la ciudad del Tormes). Era una residencia de chicos rurales, la mayoría fracasados en la escuela del pueblo. Yo era uno de sus fundadores y, una noche, la del 26 de octubre de 1978 , al leer juntos la prensa tras la cena, nos encontramos con el debate creado en torno al aumento de una hora -la sexta- en la jornada laboral de los maestros. Estaban a punto de lograr un salario más digno y asentar su profesionalidad con la jornada exclusiva, sin tener que recurrir a dar clases particulares a los hijos de alguna familia más pudiente. Pues bien, Equipo-escuela sostenía en el diario que la sexta hora con los alumnos sería antipedagógica y antipsicológica; aportaban una curva en caída libre para representar el rendimiento

maestra. Editorial», ibídem, 369 (2007), p. 3; y MARTí Soler, M.: «Magisterios con huella. Lorenzo Milani», ibidem, pp. 8-9.

33 Fabricio Caivano acudió a Madrid el I6.Io.I999 para la presentación de nuestra revista Educar(NOS) [cf. n. ${ }^{\circ}$ 8, (I999)] y, más tarde, a Peñaranda de Bracamonte, donde ensayamos un proyecto colectivo y municipal: «Educarnos en Peñaranda», $c f$. Educar(NOS), i8 (2002), monográfico.

34 Cuadernos de Pedagogía 233 (1995), pp. 38-46.

35 Destacan la Revista de Pastoral Juvenil (de los escolapios) con cuatro artículos en $1972 \mathrm{y}$, con un monográfico, Sínite, 49 (1976), de los Hnos. de La Salle. El País, 8.6.1982, se hizo eco de la «Primera promoción de una escuela milaniana en Salamanca» con una crónica de M. ${ }^{a}$ M. Rosell. Meses antes, el r.Ir.1981, Televisión Española había dedicado un programa entero de M. Torreiglesias, Voces $\sin$ Voz, a la escuela Agraria Lorenzo Milani de Salamanca bajo el título «¿Trabajar en el campo? No gracias». Fue muy seguido en toda España (no había más que dos canales entonces). En Andalucía, García López, C.: «El MEM. La pedagogía de Barbiana en España», Patio Abierto [ICE de la U. de Cádiz], 5 (1983), pp. I4-I8. 
escolar de los niños durante las últimas horas de la tarde. Al leerlo, ni los chicos de la Casa, ni los autores de Carta a una maestra, ni yo mismo podíamos entenderlo, así que envié esta carta abierta a Equipo-escuela, que el periódico publicó. Es un buen botón de muestra de cómo en cualquier propuesta pedagógica se enredan los intereses de alumnos, familias y profesores; y de cuánto trabajo cuesta introducir planteamientos sociales y de clase.

\section{NO A LA PÁGINA PEDAGÓGICA DEL JUEVES ${ }^{36}$}

Me he quedado perplejo leyendo la página preparada por Equipo Escuela sobre la sexta hora que se quiere añadir al horario de la EGB.

Es evidente que hay una zona del problema que toca lo laboral y salarial y se convierte en una cuestión de convenio colectivo del gremio, que tendría tratamiento específico en el Ministerio de Trabajo, aspecto en el que pueden los maestros quejosos contar con mi apoyo y con el de todos los gremios de trabajadores de este país, supongo, si, bien informados, coincidimos con ellos en la injusticia o discriminación que padezcan.

Mi alarma no proviene de ahí, sino de la Introducción de argumentos pedagógicos y psicológicos para negarse a un aumento de horario.

Me parece, queridos amigos de Equipo Escuela, que se os han pasado dos detalles de alguna importancia:

Primero. La Pedagogía y la Psicología también tienen clase social. (Hay muy pocas cosas asépticas socialmente en esta sociedad). Y lo que falta en vuestra página -o yo no lo veo- es un planteamiento de clase aplicado a la escuela. No es lo mismo dejar a un niño en la calle a las 5:30 de la tarde si va a caer en un ambiente familiar en el que sigue aprendiendo -por cierto, a veces, cosas más importantes que las escolares del sistema actual-, que dejarle en un ambiente callejero radicalmente inculto en el que apenas aprende cosas útiles para la escuela, estropea el lenguaje, se extrahabitúa al ocio y, con frecuencia, ni goza siquiera del contacto familiar, porque el padre es pluriempleado, la madre tal vez también y, si se trata de ambientes rurales, él mismo tiene que ocuparse de faenas de casa como atender el ganado, etc.

Todo el mundo sabe que los ocios de los ricos son formativos (juguetes educativos, cuentos, dibujos, manualidades, conversaciones con adultos más desocupados que hablan bien, que entienden sus asignaturas, que les inician insensiblemente hacia intereses culturales, que le resuelven dudas frente a un televisor, una revista seria, etc., etc.), mientras que los ocios de los pobres empobrecen más (el alcoholismo también tienen clase social, la delincuencia juvenil no digamos, el callejear de un niño día tras día sería educativo hasta un cierto punto...).

Pero lo que no sé bien si sabe todo el mundo es que las consecuencias escolares de éxitos y fracasos también tienen clase social: que suspenden, repiten y abandonan en su mayoría los hijos de las clases trabajadoras, mientras que llegan hasta la universidad, en su mayoría, los hijos de los mejor instalados. Y la causa -muy compleja- hay que atribuirla también al ambiente familiar. Cuando este país implante una escuela «igual para todos» yo no me alegraré, porque los ricos seguirán con ventaja. Aquí, de momento, y en revancha de tantos años de injusticia gravísima en este terreno, hace falta una escuela compensatoria, mejor para los menos dotados

36 El Adelanto, 3I de octubre de 1978. 
familiarmente. Y eso supone una escuela más larga para quien no la prolonga en su casa ni con la familia ni con profesores pagados de inglés, de judo, de pintura, de solfeo, etc., etc.

Este punto lo echo mucho de menos en vuestra página. Y hay que buscarle soluciones menos generales que las que piden al Estado sueldos que impidan el pluriempleo y el chaperón nocturno de los padres, que sustituya los bares por bibliotecas de adultos, los descampados por jardines, los golfos callejeros por educadores ambulantes pagados, etc., y eso por dos razones, porque son soluciones óptimas, pero a excesivo largo plazo y porque quien las pide del Estado se olvida que él ya es Estado, maestro estatal pagado por todos con una misión neta: llevar a los desiguales españoles a la igualdad de una cultura general y básica, que los pobres no alcanzan por sí solos. ( $\mathrm{i}$ tendrán que hacerse sus escuelas privadas para lograr este derecho? Si esto sigue así me parece que va siendo mi tesis. Si la Escuela estatal no puede dejar de ser interclasista, y no consigue ser compensatoria, no vale para los pobres: necesitan un complemento. El proyecto de escuela pública debería aclararse en este punto so pena de ser una vez más el timo de la estampita. Y quienes defienden la privada deberían también aclarar si están dispuestos a hacer este servicio o a reforzar a los fuertes o, simplemente, a quedarse entre dos aguas y que se beneficie el que pueda).

Que los chicos no quieren más escuela -ilustrado hasta con gráficas tremendamente discutibles- es mucho decir. Yo creo que se os ha escapado: denota nuestra incapacidad de hacer una escuela decente, nuestro inconsciente-que contagiamos a los niños- de que la escuela es un mal y la vacación un bien, de que con poca escuela es suficiente (repito: ¿para todos?). En vuestra página aparece la división entre listos y torpes, pero no es la única y la Sociología la ilustra haciéndolos coincidir -en demasiados casos- con ricos y pobres. ¿Vamos a ser incapaces de hacer una escuela interesante para los pobres?

Segundo. Tengo la impresión de que habéis caído en la trampa, porque no sé por qué todo parece últimamente dirigido a desprestigiaros como cuerpo. Hasta vuestras huelgas son diferentes (y pienso que de seguir el Ministerio así, por pureza del lenguaje, habría que cambiarlas de nombre), ya que en las huelgas ordinarias retienen el salario. Educación y Ciencia no lo suele hacer. ¿Será por miedo? Me parece que ahora, entrando vosotros mismos en la palestra con estos argumentos, contribuís al desprestigio propio. De momento, porque a la opinión pública, antes de interesarle por qué justas razones no queréis trabajar con niños una hora más, le interesa saber por qué trabajáis tantas menos a lo largo del año, respecto a los demás trabajadores del Estado y del país. Los tres meses de vacaciones y los otros trozos de Navidad y Pascua, más los puentes, etc., nunca se han entendido bien, aunque os remito de nuevo al punto uno, ya que no es lo mismo para quien lleva el niño a la playa y al monte, que para quien lo tiene tres meses en el barrio Garrido, pongamos por caso.

Yo sé por experiencia propia que supone una tensión agotadora dar clase a diario, pero me pregunto muchas veces si es mayor que la que soportan muchos padres de mis alumnos, obreros de la construcción, del metal, en Alemania a veces y en Sui$\mathrm{za}$, con controladores horarios de rendimiento, que les descuentan constantemente por hora fallida o les aumentan hasta algunos minutos diarios para recuperar una fiesta extra o poder practicar un puente. Y me lo pregunto, no porque su situación 
me parezca un modelo de trabajo, sino que-como educador de sus hijos- no quiero que me digan «señor maestro» (y menos si me consideran un señorito).

Entonces os ruego que aclaréis estos puntos: ¿en la lucha social por quién estáis? ( $\dot{O}$ es que no estáis todos de acuerdo en ello? ¿O es que no hay lucha? ¿O es que en ella la escuela es una especie de Cruz Roja neutral y no un arsenal?).

Y según eso, ¿cuál es vuestra estrategia? ¿Son de fiar vuestros consejeros «militares», esos psicólogos y pedagogos que citáis? ¿Enseñaban (y experimentaban) a pobres o ricos? El estúpido (¿científico?) que ha dicho que un niño de 6 años no rinde más de dos horas diarias y, uno de io, sólo cuatro, estoy seguro de dos cosas: no era un agricultor y tenía una escuela peor que las nuestras, pero ¿qué hacía con sus hijos el resto del día? ¿Se lo habéis preguntado?

A muchos padres creo que les interesarán estas cuestiones: ahora que proponéis una escuela pública, en la que decís que van a tener parte, querrán saber si os van a tener enfrente o al lado. Explicad bien qué estáis dispuestos a hacer con más justicia y rapidez que el Ministerio, porque es muy urgente una escuela nueva. De momento, la $6^{a}$ hora ¿ no podríais hacerla revertir en beneficio exclusivo de los perdedores?

José Luis Corzo Toral, Casa-Escuela Santiago Uno

No me detengo en otros detalles anecdóticos de la respuesta que obtuvo aquella carta y, menos aún, en recordar al lector mi estima personal por aquel colectivo de profesores, que alentó no solo la polémica en la prensa, sino una verdadera renovación pedagógica ${ }^{37}$. Pero desde entonces me queda la íntima convicción de que Barbiana chocaba incluso con cierto profesorado "progresista». Obstáculos burocráticos -como la bagatela de que el MEM sea de ámbito nacional y no autonómico- siguen impidiendo al MEM formar parte de la red española de Movimientos de Renovación Pedagógica, aunque dicha red sigue bien amarrada a la Administración gubernamental, ya sea socialista o del Partido Popular. Es una prueba más de la absorción del cambio realizada por la Pedagogía oficial (Ministerio y Universidad) y consentida por muchos movimientos pedagógicos renovadores.

\subsection{Algunas estructuras escolares milanianas}

Un rasgo de gran interés en la acogida de esta pedagogía entre nosotros es que fue aplicada muy pronto -con más o menos fidelidad o acierto, es decir, creatividad-a la realidad escolar española. De hecho, la Casa-escuela Santiago Uno (197I) nació de la simple lectura de la Lettera a una professoressa (1967), antes de contactar con exalumnos y colaboradores de Milani, con los que después entablamos

37 Respondieron bajo gran titular «A José Luis Corzo» el 9 de noviembre en el mismo periódico narrando la visita que realizaron a la Casa-escuela para dialogar sobre aquellas discrepancias: «Creemos que a ambas partes les habrá venido bien escuchar la información y la perspectiva del otro»; y en un nuevo artículo explicaban que «con la reivindicación de la sexta hora como 'no' lectiva, sin niños, pero obligatoria si se optaba, se abría una puerta, una posibilidad real, de poder caminar [mediante la formación in situ del profesorado] a una calidad de la enseñanza en la escuela», lo que el Ministerio truncó. 
con gran fortuna estrechas amistades. Esto dice mucho a favor de Barbiana y de sus textos: inspiran ideas y nuevos caminos metodológicos y organizativos.

La Casa-escuela Santiago I y la Escuela Agraria Lorenzo Milani (1980) son las dos estructuras educativas más conocidas y visitadas desde su creación. Ambas de titularidad de los religiosos escolapios. No así el $M E M$, Movimiento de Educadores Milanianos (1982), que ha participado en escuelas de verano por toda España y ha impartido diferentes cursillos didácticos, en especial sobre la lectura de la prensa en el aula y sobre la escritura colectiva. Sendos libros plenamente hispanos sobre estas dos técnicas escolares se abrieron su propio camino con notable éxito y divulgaron indirectamente el conocimiento de Barbiana ${ }^{38}$. El MEM celebró también las Jornadas del XXV aniversario de Carta a una maestra en Madrid (diciembre 1991) con la presencia, en varios de estos cursos y ocasiones, de exalumnos de Barbiana, especialmente de Francuccio Gesualdi, del Centro Nuovo Modello di Sviluppo de Pisa, del que hemos traducido diversas obras al español ${ }^{39}$. El Boletín del MEM (1982-1997) y su actual revista trimestral Educar(NOS) (1998) abierta en www.amigosmilani.es completan la larga aportación salmantina.

Otra estructura, por desgracia, menos conocida, pero esencial, es el apoyo después de la escuela a los últimos de la clase y de la sociedad (doposcuola). Alguno nacido en Italia en el 68 se halla también en España, como las escuelas «de la paz» promovidas por la Comunidad de San Egidio; otros son autóctonos, como el de Orcasitas, un barrio periférico madrileño donde una religiosa escolapia, la M. Rosa Blanco, captó perfectamente su necesidad. También en Mexicali las «escuelas de tareas» organizadas para los últimos por el escolapio Pep Segalés llevan algún componente milaniano en su ADN. Lo mismo sucede en Sevilla con la «educademia» de repasos de Manuel Pérez Real plenamente orientada a los más desfavorecidos.

En Bilbao, la Fundación Peñascal -iniciada por los escolapios y destinada a la Formación Profesional- mantiene su inspiración barbianesa desde hace muchos años y cuida con ella la formación permanente de sus profesores y maestros de taller.

La Orden de las Escuelas Pías (gratuitas), varias veces mencionada y fundada por san José de Calasanz (I557-I648), creador de la primera escuela pública europea, ha protagonizado una notable acogida de Lorenzo Milani, aunque informal y dispersa en varios lugares del mundo. Queda por investigar y escribir la relación

${ }_{38}$ El más famoso es un libro colectivo: Casa-escuela Santiago i de Salamanca: Escritos colectivos de muchachos del pueblo, Madrid, Popular, 1979, ${ }^{3}$ I982; hoy en Salamanca, ACC, ${ }^{4} 1996$, con ilustraciones de J. L. Cortés. También, Corzo, J. L.: La escritura colectiva. Teoría y práctica de la escuela de Barbiana, Madrid, Anaya, 1983, cuya traducción al italiano en colaboración con el exalumno de Barbiana F. Gesualdi lleva un epílogo de P. Freire: Don Milani nella scrittura collettiva, Torino, Gruppo Abele, 1992. Objeto de múltiples cursillos por toda España: Conzo, J. L.: Leer periódicos en clase, Madrid, Popular, 1987, ${ }^{3}$ 1992. Cf. también id.: Educar es otra cosa. Manual alternativo entre Calasanz, Freire y Milani, Madrid, Ed. Popular, 2007, y Educarnos con la actualidad. No viene en el libro pero entra en el examen, Madrid, PPC, 2000.

${ }_{39}$ La principal es Centro Nuevo Modelo de Desarrollo, Norte-Sur, la fábrica de la pobreza, Madrid, Popular, ${ }^{3}$ I997; también Geografía del Supermercado mundial, Pamplona, Setem, 1998. 
de don Milani con escolapios concretos italianos y españoles, a comenzar por el famoso P. Ernesto Balducci ${ }^{40}$. Pero, como es lógico y fruto de la dualidad barbianesa ya descrita -útil contra el fracaso escolar y demasiado alternativa contra la escuela «normal»- esta acogida también es oscilante; a veces, impulsa lo meramente asistencial, sin alcanzar la conversión pedagógica que pide y brinda Barbiana.

En la Córdoba andaluza existía desde hace muchos años cierta Asociación «Barbiana» con la que descubrimos recientemente una gran sintonía. Un sacerdote cordobés, Paco Aguilera, lector en su día de Milani, no había dudado al nombrar su trabajo en la promoción social de su barrio. Hoy trabajan con adolescentes de Enseñanzas Secundarias el compromiso social y político, sin que predomine el doposcuola. El MEM celebró su penúltimo encuentro allí con ellos en 2012 y se iniciaron en un curso de escritura colectiva, por ejemplo.

En la Córdoba argentina (Argüello), en cambio, existe una Fundación Lorenzo Milani para educación y rehabilitación de discapacitados con un hogar ad hoc. Y es muy posible que en tantos otros sitios abunden más agrupaciones educativas por el estilo, que nos gustaría mucho conocer.

\subsection{Presencia de Barbiana en la universidad española}

Tampoco aquí puedo ser exhaustivo y, mucho menos, acusador. Al revés, prefiero subrayar los méritos de Barbiana por haber llegado tan alto en pocos años, siendo como era una escuelita rural.

En el ámbito universitario eclesiástico don Milani tiene también un lugar teológico-pastoral que implica a las facultades de Teología y Educación de la propia Iglesia católica y a sus editoriales y revistas ${ }^{41}$. Todo el mérito, pues, en primer lugar a mi universidad, la Pontificia de Salamanca, que admitió ya en $1980 \mathrm{mi}$ tesis doctoral en Teología, la editó inmediatamente y su revista Salmanticensis ha acogido algún artículo especializado ${ }^{42}$. Pero también lo ha hecho así su Facultad

40 Balducci, E.: L'insegnamento di don Lorenzo Milani, Roma-Bari, Laterza, 1995, recoge una docena de sus artículos dedicados a Milani. Otros escolapios frecuentaron Barbiana, como Lodovico Grassi, Giovanni Landucci, Adelio Pagnini, Franco Scarsella o, españoles, como Jesús Lecea y Miquel Martí, y también alguna religiosa calasanziana, sor Giovanna. En Carta a una maestra queda una dura constatación: «Ciertos colegios de curas son más honrados. Son instrumento de la lucha de clases y no lo ocultan a nadie. En los Barnabitas de Florencia el precio de un mediopensionista es de 40.000 liras al mes. En los Escolapios, 36.000» (o. c., p. 74). El P. General Ángel Ruiz Isla impulsó contra viento y marea en I971 la fundación de la Casa-escuela Santiago Uno de Salamanca cuando era superior provincial de Castilla.

${ }^{41}$ El propio cardenal MARTini intervino en el Congreso convocado por la Universidad Católica de Milán (9-1o de marzo de 1983) entre especialistas de alto nivel universitario: «L'esperienza pastorale di don Milani oggi», en Don Lorenzo Milani tra Chiesa, cultura e scuola, Milano, U. Cattolica, 1983, pp. 198-2008, con una bellísima Introducción de G. Lazzati.

${ }_{42}$ Corzo, J. L.: «Una escuela cristiana aconfesional, la de don Milani», Salmanticensis, I (1978), pp. 67-87. 
de Educación en su propio campo y en ello destacan varios profesores, como veremos. La BAC, editorial de la Conferencia Episcopal Española, ha destacado sobremanera al editar la mencionada traducción de Experiencias pastorales.

En la Pedagogía universitaria española el eco académico general es menos halagüeño, pero no insignificante, como se ve a través de alguna bibliografía:

Por ejemplo, hay que señalar la temprana resonancia de O. Fullat ${ }^{43}$ : Filosofías de la educación, Barcelona, Ceac, 1978, pp. 409-428, y de J. M. Quintana Cabanas: La pedagogía moderna, Noguer, 1978, pp. I00-IоI.

No falta la presencia de Milani en algunos manuales de Pedagogía: apenas alguna cita alusiva en J. Gimeno Sacristán y A. Pérez Gómez: Comprender y transformar la enseñanza, Madrid, Morata, 1992, p. 214; A. J. Colom y otros: Teoría e Instituciones contemporáneas de la educación, Barcelona, Ariel, I997; M. Carreño: Teoría e Instituciones contemporáneas de educación, Madrid, Síntesis, 2002; O. Negrín y J. Vergara: Teoría e Instituciones contemporáneas de educación, Madrid, Centro de Estudios Ramón Areces, 2003; M. M. del Pozo: «Lorenzo Milani o la pasión por enseñar», en id. (ed.): Teorías e instituciones contemporáneas de educación, Madrid, Biblioteca Nueva, 2004, pp. 277-281; y J. Monés: La pedagogia catalana al segle XX. Els seus referents, Lleida, Ed. Pagès, 20II, pp. 365-369.

Una mayor extensión e importancia le concede A. García Madrid: «Lorenzo Milani y la escuela de Barbiana», en su Educación: teorías e institucionalización, U. Pontificia de Salamanca, 20I2, pp. 177-219; así como también una repetida atención -en escritos y cursos específicos- le ha prestado el profesor de la Universidad de Girona X. Besalú: Diversidad cultural y educación, Madrid, Síntesis, 2002, pp. 155-190 y 237-243; La formación del profesorado en Educación Intercultural, Madrid, Los Libros de la Catarata, 2004, pp. 49-92; y junto a I. Vila: La buena educación. Libertad e igualdad en la escuela del siglo XXI, Madrid, Ediciones de la Catarata, 2007, pp. 2I-56 y I45-I86; así como en su Pedagogía sin complejos, Xàtiva, L’Ullal-Instituto Paulo Freire, 20IO, pp. 47-49, 88, 97, I5I, I6I, 175-177, 24I, 265-270.

En cuanto a diversas didácticas: A. Romero: «El valor de la palabra en la escritura colectiva», en Técnicas didácticas para la enseñanza de la composición escrita en Educación básica, Univ. de Granada, 1989, pp. I43-153; y, años después, B. Delmiro: La escritura creativa en las aulas. En torno a los talleres literarios, Barcelona, Graó, 2002, pp. 48 y ss. Destaca X. R. Jares: Educación para la paz. Su teoría y su práctica, Madrid, Popular, ${ }^{3} 2005$, pp. $93-95^{44}$. F. Lara: «La escuela milaniana», en La escuela como compromiso, Madrid, Ed. Popular, 2004, pp. 76-80; y Piergiorgio Reggio: El cuarto saber. Guia para el aprendizaje experiencial, Xàtiva, Edicions

43 Octavi Fullat (1928), catedrático de Filosofía de la Educación en la U. de Barcelona, también es escolapio, como yo mismo.

${ }_{44}$ Este catedrático de Didáctica de La Coruña, verdadero especialista de la educación en el conflicto y la paz, tal vez no sepa, al encomiar a E. Fromm [cf. Sobre la desobediencia y otros ensayos, Barcelona, Paidós, 1984] que quiso biografiar a Milani, fascinado por su «obediencia ya no es una virtud, sino la más sutil de las tentaciones» en su Carta a los Jueces de 1965. Cf. su «Educar para la desobediencia», en Etxeberria, Xabier (ed.): Enfoques de la desobediencia civil, Bilbao, Univ. De Deusto, 200I, pp. 97-I20. 
del Crec, 20IO, pp. I39-I43. también el mordaz análisis de la realidad de J. J. Romera: Retrato canalla del malestar docente, Córdoba, Toro Mítico, 2010.

Sin duda, la lista de las omisiones sería mucho más larga..., pero no solo en España; también las hay en la propia Italia, como simboliza una traducción italoespañola -muy justificada en el Prólogo de Carme Sala- de Franco Fabbri: El libro de la Pedagogía y la Didáctica, 3 t., Madrid, Popular, 200I-2, ilustre profesor de Bolonia, que, junto a Reggio Emilia, son el fulcro de la pedagogía italiana. Silencio sobre la Lettera, por ejemplo.

Conviene recordar que la Pedagogía es una especialidad universitaria reciente, que en España no logró emanciparse hasta los años 70 de la Facultad de Filosofía y Letras, en la que había nacido en 1932 con la II República ${ }^{45}$, y que, transformada enseguida en Ciencias de la Educación, hubo de modelar con prisa su propia identidad, ¡y científica! No es convicción mía en exclusiva que la universidad formatea lo pedagógico a su imagen desde esos años, como ya leímos en el prólogo de J. Carbonell a Pedagogías del siglo XX (Barcelona, 2000) y en tantos otros.

\section{Conclusión}

Que la Pedagogía no es una ciencia instituida, aunque deba estudiarse a conciencia, ya se ha demostrado muchas veces, cada vez que irrumpen en ella espontáneos valiosos ( $\mathrm{y}$ no han sido pocos entre los hoy considerados pedagogos históricos).

Próximos ya al medio siglo de la muerte de Milani y de la Carta a una maestra (ambas en 1967) podemos decir que su simiente se ha esparcido y recogido en buenas tierras de labor educativa y también en la letra de muchos libros. Por eso nos gustaría conocer muchas más realidades concretas iberoamericanas y portuguesas, porque las inquietudes que suscitó la Carta siguen despertándose aquí y allá. Tales inquietudes son también la razón -seguro- del silencio con que muchos acogen esta pedagogía: denuncia la injusta desigualdad que rige nuestro mundo en crisis y que, gracias a la mala educación, se expande y afianza con disimulo por todas partes.

45 Cf. Hernández Díaz, J. M. (ed.): Pedagogía para el siglo XXI. 25 años de Pedagogía en la Universidad de Salamanca, Salamanca, Globalia, 2003. 